\title{
Aliança de Ecoversidades: uma experiência de cinco anos em aprendizagem cosmopolítica
}

\author{
Udi Mandel' \\ Gerardo Lopez-Amaro' \\ Kelly Teamey' \\ 'Enlivened Cooperative - Estados Unidos da América
}

\begin{abstract}
RESUMO - Aliança de Ecoversidades: uma experiência de cinco anos em aprendizagem cosmopolítica. De que maneira o ensino superior pode ser reinventado de maneira a incluir múltiplos sistemas de conhecimento, por um mundo em que muitos mundos co-habitem? Esta é uma das perguntas no cerne da Aliança de Ecoversidades, uma aliança planetária de lugares e profissionais de aprendizagem que reinventam o ensino superior, muitos oriundos de movimentos sociais e ecológicos e de comunidades indígenas. Constituída por mais de 400 integrantes, representando mais de 260 organizações em torno de 47 países, a Aliança de Ecoversidades está engajada em experimentar, aprender e praticar modos de regeneração de ecologias, culturas e economias locais e enfrentar o ódio, a violência, a monocultura, o extrativismo, o superconsumo e a exploração. Este artigo irá se embasar na perspectiva de três de seus integrantes que foram participantes chave desde sua criação em 2015 - na condição de cofundadores e integrantes do comitê de direção, refletindo sobre sua aprendizagem na/com a Aliança. Este artigo enfoca a maneira como a Aliança vem tentando fazer aquilo que estamos denominando aqui de aprendizagem cosmopolítica: aprender como aprender em e entre culturas, epistemologias, ontologias; aprender a aprender a partir de, na e além da diversidade.

Palavras-chave: Reinvenção do Ensino Superior. Ontologia Política. Cosmopolítica. Movimento do conhecimento.
\end{abstract}

ABSTRACT-EcoversitiesAlliance:afive-year experimentincosmopoliticallearning. How can higher education be re-imagined so as to include multiple knowledge systems, for a world where many worlds co-inhabit? This is one of the questions at the heart of the Ecoversities Alliance, a planetary alliance of learning places and practitioners reimagining higher education, many of them emerging from social and ecological movements and indigenous communities. Constituted by more than 400 members, representing over 260 organizations in around 47 countries, the Ecoversities Alliance is engaged in experimenting, learning from and practicing ways to regenerate local ecologies, cultures and economies and challenge hatred, violence, monoculture, extractivism, overconsumption, and exploitation. This paper will draw from the perspective of three of its members who have been key participants since its birth in 2015 - as co-founders and steering committee members, reflecting on their learning in/with the alliance. This paper focuses on how the Alliance has been attempting to do what we are calling here cosmopolitical learning: learning how to learn in and between cultures, epistemologies, ontologies; learning to learn from, within, and beyond diversity.

Keywords: Re-Imagining Higher Education. Political Ontology. Cosmopolitics. Knowledge Movement.

Educação \& Realidade, Porto Alegre, v. 46, n. 4, el18644, 2021. 
Aliança de Ecoversidades

\title{
Introducão. Surgimento, inter-ser e a crise do One- World World
}

\author{
Tu beso se hizo calor \\ Luego el calor movimiento \\ Luego gota de sudor \\ Que se hizo vapor, luego viento [...] (Jorge Drexler, Todo se \\ transforma, 2004).
}

É difícil escrever-pensar-sentir o surgimento em um computador. Assim, estou escrevendo isso a lápis por extenso no meu caderno. Sem nenhuma tela à minha frente, enxergo o oceano e escuto as ondas quebrando. E muito provavelmente você, caro leitor, agora lê estas palavras em uma tela. Um som-imagem do mar pode surgir em sua própria consciência; este milagre composto de comunicação através do tempo e do espaço, tão frequentemente despercebido, baseado em inúmeras práticas, trabalhos e relações tecnológicas, sociais e cognitivas. Quando o ativista budista engajado, profissional e autor Thich Nhat Hanh (2002) nos convida a olhar para uma folha de papel em branco, como estou fazendo agora, para desembaralhar os processos e as práticas que entraram em seu fazer - a nuvem e a chuva, a luz do sol, o trabalho do lenhador, o alimento que o alimentou o e os pais que o criaram -, está nos desviando do mundano rumo ao milagroso e ao composto, para o nosso inter-ser.

'Inter-ser' é uma palavra que ainda não consta no dicionário, mas se combinarmos o prefixo 'inter' com o verbo 'ser', temos um novo verbo, inter-ser. Sem uma nuvem não podemos ter o papel, então podemos dizer que a nuvem e a folha de papel inter-são (Nhat Hanh, 2002).

É claro que não podemos ter nuvens sem o beijo, o calor, o movimento, o suor e o vapor. Inter-ser é um conceito suado, um dos muitos que iremos usar ao longo deste artigo para compartilhar alguns pensamentos e práticas incorporadas relacionados à Aliança de Ecoversidades. Para deslocar o foco, muitas vezes (objetivamente) distanciado e racionalizado, do fazer sentido e da aplicabilidade conceitual, exploramos e jogamos com o uso de um 'conceito suado' de Sarah Ahmed, que incentiva cada um de nós a enxergar/escutar/saborear/cheirar/ sentir - e suar - conceitos que "estão em ação em qualquer coisa que fizermos", especialmente quando estão saindo de "um corpo que não está em casa no mundo" (Ahmed, 2017, p. 12-13). Alguns conceitos são suados, nascidos do devir individual e coletivo no mundo, às vezes por meio de choque ou dissonância. Outros conceitos estão se tornando palavras, como a tradição koan no zen budismo em que uma expressão é colocada à mente que, incapaz de aplicar o raciocínio habitual, enxerga seu próprio reflexo e é liberada (isto é, qual é o som de uma mão aplaudindo?). Da mesma forma, o conceito de cosmopolítica, com o qual dançamos neste artigo, é um conceito suado para nós. Tem vivido conosco em nossa experiência de cinco anos com a Aliança de Ecoversidades, não necessariamente neste exato teor, mas em seu espírito e prática. 
A cosmopolítica também é um conceito de virada, cunhado primeiramente por Isabelle Stengers (2005) como um antídoto, uma desaceleração (como um koan no zen budismo) das práticas e dos processos dos compromissos ontológicos característicos da modernidade. Estes compromissos são baseados em princípios newtonianos e cartesianos em que todos os recursos e seres do mundo são uma coletânea de objetos que podem ser medidos, quantificados e ter suas trajetórias previstas sob o triunfo da razão e da ciência, universalizados para o progresso e o desenvolvimento como regime de verdade moderno/colonial. Este OneWorld-World [Um Único Mundo] (Law, 2015) assumiu para si o direito de ser "O" mundo, sujeitando todos os outros mundos aos seus próprios termos e, assim, estipulando programaticamente seu apagamento. O One-World-World (OWW) enfrenta uma crise civilizacional urgente pela qual a humanidade, interconectada aos sistemas planetários e toda sua rede de vida, enfrenta desafios e fenômenos complexos que são uma consequência direta dos valores e práticas que orientam o OWW. A enorme quantidade de desafios simultâneos enfrentados por todos nós se sobrepõe e deveria ser tratada como sistemas que interagem, não como fenômenos isolados: eventos climáticos extremos, crise climática, degradação de ecossistemas, erosão do solo, diminuição das reservas de água potável, perda de biodiversidade, degelo da permafrost, a sexta extinção em massa de espécies, pesca predatória, aprofundamento das desigualdades e prevalência de sistemas de opressão, crescimento dos fundamentalismos, deslocamentos forçados, epidemias e pandemias, feminicídios, guerras e opressões sistêmicas.

Por muitos anos, nós três sentimos os altos e baixos suados da aprendizagem, da pesquisa e da docência dentro dos muros do ensino superior. Desde nosso primeiro encontro em 2013, quando a semeadura inicial da Aliança de Ecoversidades começou a emaranhar pessoas afins como nós, temos executado uma dança de entrada e saída da academia. Nela tivemos uma miríade de encontros suados se esfregando contra a crescente rigidez do ensino superior, na medida em que progressivamente se racionaliza rumo a finalidades neoliberal e gerencialistas. Observamos como a mercantilização de todas as fases da produção de conhecimento tomou conta. Pelias descreve uma "crise de fé" sentida por aqueles que procuram trabalhar dentro dos muros da academia com seus corações apaixonados na linha de frente:

Lecionavam para estudantes que pareciam mais interes-
sados nas notas do que em aprender. Trabalhavam para
administradores que pareciam mais preocupados com
os resultados finais do que com a educação de qualida-
de. Compareciam a infinitas reuniões que não pareciam
ser interessantes, elaboravam relatórios sem sentido que
pareciam desaparecer na burocracia, e aprendiam que o
serviço parecia ter pouco efeito na vida dos outros. Produ-
tividade era o lema do dia, então publicavam artigo após
artigo que ninguém parecia ler, particularmente aqueles
que eram o foco do estudo. Escreviam texto após texto
sobre problemas sociais, mas nenhum deles parecia fazer


Aliança de Ecoversidades

qualquer diferença. Pesquisavam temas que os levaram a promoções e estabilidade, mas pareciam distantes de quem eram. Sentiam-se vazios, desanimados, desiludidos. Sentiam-se em bancarrota espiritual e ética. Então, alguns começaram a reconhecer que o imperador e, na verdade, eles mesmos estavam nus. Começaram a questionar por que a vida universitária precisava ser dessa maneira, por que tinham que se distanciar de seu trabalho, por que apenas determinadas formas de discurso contavam como conhecimento, por que não se sentiam mais conectados com aqueles estudados por eles, por que suas mentes deveria ser separadas de seus corpos, por que tinham que manter suas emoções sob controle, por que não podiam falar com o coração (Pelias, 2004, p. 10-11).

As perguntas feitas por Pelias ressoam conosco e com muitos outros colegas e amigos que também vêm coreografando suas próprias danças acadêmicas. Em nossa experiência, muitas vezes existe uma alienação de si e da finalidade, pois muitas vezes a academia convencional nos leva a distanciar nossos corações e corpos do nosso trabalho. E, de maneira mais significativa e perniciosa, existe uma relação direta entre o ensino superior e as crises ecológicas, sociais e econômicas que todos nós enfrentamos no mundo hoje (Santos, 2010; Ford, 2002; Orr, 1992; 2004). O atual sistema universitário é, por definição, projetado como um motor de regime de verdade pedagógico e epistemológico que orienta a reprodução do OWW, que tende a reificar a separação entre mente e coração/corpo; entre conhecimento e lugar; entre o eu e a comunidade.

Assim, qual é a função da universidade ao desmontar o OWW e ao permitir o surgimento de novas histórias e possibilidades, o florescimento do pluriverso ou do 'mundo onde cabem muitos mundos'? Estas perguntas e insights situam como a Aliança de Ecoversidades continua a emergir em inter-ser.

Dentro do quase imutável estrangulamento que o sistema universitário reproduz e mantém dentro do regime de verdade do OWW, houve uma crescente proliferação de universidades novas e contra-hegemônicas que surgem como respostas imaginativas às várias formas de opressão coloniais, pós-coloniais e/ou neoliberais (Esteva; Prakash, 2008), juntamente com múltiplas práticas de undercommoning (Harney; Moten, 2015). Estes novos lugares de aprendizagem estão tentando ir além de sua função atual de reproduzir a ordem social (Shukaitis; Graeber, 2007; Casas-Cortes; Cobarrubias, 2007). Buscam reconfigurar as relações de poder que as situam e, subsequentemente, oferecem múltiplos insights de como o ensino superior poderia estar a serviço das diversas ecologias, culturas, economias, espiritualidade e vida em nosso lar planetário.

Em nosso envolvimento com os debates e as práticas que tentam fazer germinar lugares de aprendizagem novos e contra-hegemônicos além da universidade modernista, aterrissamos no termo ecoversidades. Ecoversidades descreve a reorientação da aprendizagem e do co- 
nhecimento que está ocorrendo em todo o planeta. É um movimento distante da ênfase da universidade modernista sobre seus próprios paradigmas e cosmovisão como a única, a uni, a mono - a única maneira de aprender, ser, saber, fazer, relacionar-se e habitar. É um movimento rumo ao aprender, ser, saber, fazer, relacionar-se e habitar que vem de eco- do grego oikos- de nossa ecologia, nosso lar e nossas comunidades. Ecoversidades descreve estes sítios de inovação e reinvenção que estão arraigados no lugar, semeados a partir de esforços locais e buscando colocar a aprendizagem a serviço de comunidades, ecologias e espiritualidades para florescimento mútuo de todos nós.

Com múltiplas cosmologias, visões, contextos, história, línguas, e geografias, na Aliança de Ecoversidades nós nos coenredamos em um ecossistema próspero, estimulante e, às vezes, desafiador. Contamos entre nós algo em torno de 260 organizações 'integrantes' oriundas de 47 países (e de mais de 50 idiomas), e mais de 400 indivíduos com entrelaçamentos regionais ativos na América Latina, no Pacífico, na Índia, na Europa, na África, na América do Norte, na Ásia e no mundo árabe. Ser uma ecoversidade integrante significa participar de nossos diálogos e encontros e estar ativamente envolvida na construção de formas de aprendizagem fora do atual status quo. Além das reuniões periódicas (internacionais e regionais), os integrantes da Aliança também participam de jornadas de residência em intercâmbio e aprendizagem, produtos publicados e projetos colaborativos, tanto regionais como temáticos.

Este artigo é um condensado de algumas experiências importantes de aprendizagem ao participar e ajudar a alimentar a Aliança de Ecoversidades desde sua concepção. Nós três vivenciamos muitos processos, reuniões, seminários, sessões e cerimônias co-organizadas por nós e por outros integrantes da Aliança. Também escrevemos e refletimos sobre estes diversos encontros desde 2015 (ver www.Ecoversidades. org). Os autores também são integrantes atuais do Comitê de Direção, formado por seis componentes da Aliança, contribuindo para a organização desta comunidade de práticas inter(trans)culturais. Embora qualquer perspectiva sobre um fenômeno, especialmente tão complexo quanto uma Aliança com tanta diversidade como esta, invariavelmente seja parcial, nossa esperança é oferecer em nossas reflexões alguns aspectos da Aliança que possam ser de interesse a outros que lutam (e suam) para saber como praticar a aprendizagem cosmopolítica.

\section{One-World Worlde o Desafio de Movimentos de Conhecimento}

As ecoversidades abrigam múltiplas comunidades de prática e aprendizagem, ecopedagogias com experiências que respondem aos críticos desafios enfrentados pelo planeta. Algumas delas são universidades com acreditação construídas a partir do zero, flexibilizando e desfazendo as fronteiras da disciplinaridade do antigo paradigma com o pensamento mais inovador, criativo e crítico; outras criam fissuras de aprendizagem animada nas estruturas cimentadas e rígidas de uni- 
Aliança de Ecoversidades

versidades tradicionais; algumas se recusam a ficarem contidas dentro dos muros de notas e graduações; outras fazem parte de uma comunidade sustentável intencional, como ecovilas, ecobairros ou cidades de transição; algumas são sazonais e itinerantes, criando espaços intensos e condensados de convivência e exploração coletiva; outras surgiram como parte de movimentos indígenas, feministas, negros, jovens, sociais e ambientais como uma dimensão importante das lutas traduzidas em pedagogias para formação de rebeldes competentes; todas elas multiplicam e alimentam a riqueza de experiências, práticas, teorias, ideias e horizontes de possibilidade em cada de seus territórios, urbano ou rural. Os projetos assumem muitas formas - universidades holísticas, vilas e ecovilas tradicionais, ashrams, cafeterias, espaços de co-working, prisões, embaixo de pontes, favela urbanas, fazendas, barbearias e similares. De zonas provisórias de aprendizagem autônoma a campi bem-estabelecidos, as Ecoversidades prosperam de muitas formas, texturas e cores diferentes. Sobretudo, nos enxergamos como um movimento de conhecimento emergente.

Este movimento do conhecimento que é lentamente construído no mundo inteiro, muitas vezes sob o radar da mídia (convencional e outras), é uma rede emergente de pessoas e comunidades que reivindicam seus sistemas e imaginações de conhecimento local para restaurar e reimaginar processos de aprendizagem que sejam significativos e relevantes ao chamamento de nossos tempos. Apesar de diversificado em suas origens, este movimento do conhecimento se engaja não apenas ao criticar e resistir aos nossos sistemas educacionais falidos, mas também ao cultivar novas histórias, práticas e possibilidades que reconectem e regenerem a aprendizagem em ecossistemas ecológicos e culturais locais. Estamos testemunhando um movimento na cocriação de conhecimento e des/re/aprendizagem que se distancia da aspiração modernista ao uno e universal para/dos muitos - aquele que sustenta e anima (tanto o humano como o além-humano). De maneira similar às tendências de movimentos sociais que surgem na América Latina, este movimento do conhecimento prioriza a decolonização epistêmica; amplia os discursos sobre o modelo de nossa crise de civilização global por meio de alternativas ao desenvolvimento; e coorganiza de maneira a centralizar a lógica e a relacionalidade comunal (Escobar, 2018). O embasamento teórico deste trabalho é informado por críticas decoloniais (Andreotti et al., 2015; Grosfoguel, 2013), indígenas (Chambers; Blood, 2010; Martinez Luna, 2015), anticapitalistas (Santos, 2010; Harney; Moten, 2015; Shukaitis; Graeber, 2007) e ecológicas da universidade e da epistemologia e ontologia da modernidade (de la Cadena; Blaser, 2018; Escobar, 2016; Ford, 2002; Ingold, 2017; Orr, 2004). Autores como Santos descrevem o que estamos referindo aqui como movimento do conhecimento para a justiça global, incluindo o fim do império cognitivo e abrindo espaço para uma ecologia de saberes (Santos, 2018). Outros, como Escobar (2016), de la Cadena e Blaser (2018), colocam esta reconfiguração da episteme do momento histórico atual por meio do conceito de pluriverso como "mundos socionaturais heterogêneos parcialmente 
conectados que negociam politicamente suas discordâncias ontológicas” (de la Cadena, 2015, p. 360). Fazer a transição da globalização para o pluriverso significa pensar sobre "a multiplicidade de mundos mutuamente emaranhados e coconstituintes, apesar de distintos" (Escobar, 2016, p. 22). Uma aspiração frequentemente atribuída aos zapatistas coloca isso de maneira sucinta: "Queremos habitar um mundo onde muitos mundos co-habitem".

Antes do surgimento dos zapatistas como um movimento social mais recente (Day, 2004; 2005), as estratégias e as táticas para a mudança social pela maioria dos movimentos sociais tendiam a ser melhorias para uma sociedade mais "multicultural" ou se contrapor à hegemonia com a intenção de se tornar a nova maioria dominante. Tormey (2005) esboça diferentes concepções de utopia, explicando que enquanto um mundo utópico objetiva criar uma nova realidade social fixa e determinante (isto é, um novo OWW), os espaços utópicos intencionalmente evitam uma narrativa mestre da realidade ao estimular políticas, formulações de teoria e práticas que sejam experimentais, não-hierárquicas, localmente arraigadas, múltiplas, abertas, cocriadas e espontâneas. Este processo de espaço utópico envolve a redefinição da linha de base do político, enfrentar o conflito, romper o silêncio, tornar público o antagonismo entre mundos, interconectar "essa pluralidade sem tornar mundos diversos comensuráveis” (de la Cadena, 2010), e permitir uma desestabilização radical de quem pode ser político e o que é considerado uma questão política com quais atores, como seresalém-do-humano, como em Standing Rock, Mauna Kea ou Wirikuta ${ }^{1}$. Os movimentos sociais mais recentes, conforme Day $(2004 ; 2005)$ explica, procuram criar espaços utópicos por intermédio de afinidades de sistemas de liderança e conhecimento fora dos auspícios do Estado, propiciando maior liberdade de aprendizagem e formação da identidade. A Aliança de Ecoversidades pode ser compreendida como o mais recente movimento de conhecimento com princípios e práticas, estratégias e táticas semelhantes. Ao invés de tentar melhorar a educação apenas a partir de dentro do sistema por meio de melhorias de vários tipos, a Aliança procura fortalecer as afinidades entre estes espaços utópicos de aprendizagem, muitos deles reinventando a educação fora do sistema.O regime de verdade da modernidade, o OWW, está baseado em um arranjo específico entre a política e a epistemologia. De acordo com de la Cadena (2010, p. 359), a política surgiu com a ciência "[...] para fazer um universo vivível, para controlar o conflito entre uma humanidade única, se diversificada, que vive em uma única natureza cientificamente cognoscível”. Este tipo de política é hegemônico e diz aos seus sujeitos o que é importante e o que deveria ser desconsiderado. Por exemplo, seres-além-do-humano pertencem ao domínio da cultura indígena e nunca como entidades políticas ocorrendo em um desacordo em potencial, formulando conflitos apenas como ambientais ou disputa por recursos. As diferenças ontológicas são toleradas pelo liberalismo, mas expulsas do espaço de discussão política. Esta negação de diferença ontológica obstrui as possibilidades de alternativas à modernidade. O que está em 
Aliança de Ecoversidades

jogo é a resistência ao ontocídio buscado que abasteceu a expansão da modernidade/colonialidade desde "o longo século XVI" (Grosfoguel, 2013). A tentativa de eliminar ou subjugar a diferença e seus bolsões de resistência continua hoje, agora sob a afirmativa de uma modernidade englobante que reivindica para si a pretensão da universalidade. Um problema central com a política do OWW é "aquilo que, de um ponto de vista indígena, expressa uma negação da diferença ontológica, o estado formula como progresso, proteção e melhoria cultural" (de la Cadena, 2010, p. 347).

É necessária outra maneira de fazer política para abordar a guerra não reconhecida contra tudo que for coletivo (Escobar, 2018) que os zapatistas chamam de Quarta Guerra Mundial - uma guerra que desafia todas as fronteiras geográficas e, ao contrário, procura destruir qualquer coisa que se oponha ou obstrua o OWW e sua máquina modernista extrativista e com fins lucrativos (Marcos, 1997). Estes ataques são tão fortes que há uma urgente necessidade de transição de globalização além do OWW e, ao contrário, perceber nossa planetarização compartilhado para criar condições e possibilidades pluriversais. Mesmo assim, com o afluxo de mundos diversos que vêm a ser por movimentos de resistência, existe uma necessidade simultânea de desenvolver e permitir traduções entre processos epistemológicos complexos (Santos, 2007; Escobar, 2018), bem como múltiplas ontologias. "Assim, a transição para o pluriverso clama por um conceito expandido de tradução que envolva dimensões ontológicas e epistêmicas" (Escobar, 2018, p. 66). Estas dimensões tradutivas envolvem um tipo de justiça cognitiva que raramente é reconhecido ou inteiramente compreendido. Muitos dos inevitáveis conflitos produzidos dentro e através da Aliança de Ecoversidades surgem devido à nossa falta de ferramentas para apoiar (e às vezes até mesmo nomear) os muitos momentos em que a injustiça cognitiva ocorre, mesmo entre aqueles de nós que estejam ativamente procurando e experimentando cocriar esses encontros tradutivo. Ao longo destas linhas, Escobar descreve a geo-epistemo-política que espreita dentro e entre movimentos de mudança social e de transição e a necessidade de melhores ferramentas de tradução entre elas. Estas ferramentas poderiam permitir que estes movimentos percebessem mais intimamente quem, como e o que é incluído e excluído.

Como deveríamos considerar esta outra maneira de fazer política, aquela que reconhece os conflitos como ontológicos e o mundo como desorganizado, plural e em devir? O termo cosmopolítica, cunhado pela filósofa da ciência Isabelle Stengers, tem sido útil para articularmos isto.

Portanto, aqui o cosmos deve ser diferenciado de qualquer cosmos, ou mundo, em particular, pois uma tradição especifica pode concebê-lo. Tampouco se refere a um projeto desenhado para abrangê-los, pois sempre é uma má ideia designar algo para abranger aqueles que se recusam a serem abrangidas por algo. No termo cosmopolítica, o cosmos se refere ao desconhecido constituído por estes mundos múltiplos, divergentes, e às articulações 
das quais poderia, no fim, ser capaz, em oposição à tentação de uma paz pretensamente final, ecumênica: uma paz transcendente com o poder para perguntar qualquer coisa que seja divergente para se reconhecer como uma expressão puramente individual daquilo que constitui o ponto de convergência de todos (Stengers, 2005, p. 997).

Enquanto Stengers e Latour (2005) enfocaram as ontologias de comunidades científicas e sua interface com outros saberes e éticas que as desafiam (no caso de Stengers, estudos de movimentos contra organismos geneticamente modificados, por exemplo), os antropólogos Mario Blaser e Marisol de la Cadena exploraram como estes conceito e responsividade se engajam com o encontro de ontologias em terrenos políticos contestados relacionados à terra, aos recursos e ao desenvolvimento em determinados territórios. A obra deles, baseada em trabalho de campo com comunidades indígenas e Povos Originários no Paraguai, no Canadá e no Peru, descreve este encontro entre ontologias modernas, colonizadora e de desenvolvimento com aquelas das comunidades que habitam estes territórios. Especificamente, trazem para o foco de que maneira atores não humanos, como montanhas, florestas, rios e outros também são sujeitos e seres políticos dentro das ontologias de povos indígenas e Povos Originários.

Assumindo estas conversas de cosmopolítica, sugerimos que a noção de aprendizagem cosmopolítica captura uma responsividade e um conjunto de práticas chave que surgiram na Aliança de Ecoversidades ao longo dos anos. Neste artigo, exploramos mais o que aprender cosmopoliticamene acarretou, descrevendo os desafios e as possibilidades de aprendizagem entre as ontologias, bem como nos espaços emergentes entre eles.

Uma tarefa crucial é desafiar a instrumentalização da diferença (a criação de hierarquias opressoras e alienantes baseadas no sexo, no gênero, na raça, no idioma, na religião, na classe ou em alguma outra forma de diferença) para perpetuar sistemas violentos de injustiça e, ao mesmo tempo, encontrar maneiras de levar a sério a diferença. Isto acarreta uma pesquisa radical com solidariedade em nossas práticas de mundificação, um questionamento do tipo de articulações, pontes, tensões e relações entre eles. Este questionamento em solidariedade está refletido nos encontros da Aliança como um convite, não como uma abordagem finalizada ou acabada. A natureza emergente das reuniões e da Aliança em si através de muitos encontros e projetos é a condição de possibilidade para este encontro entre mundos que são incomensuráveis e, mesmo assim, (possivelmente) traduzíveis. O que sustenta um horizonte de iniciativas de aprendizagem translocais ganhando força ao coexistir e compartilhar é o engajamento sério com a diferença, ao contrário da maneira dominante de instrumentalizar a diferença para a perpetuação do status quo. Aqui encontramos a possibilidade de um devir em que as práticas, as tensões e os conflitos, e os erros cotidianos que são uma parte natural de cada processo de aprendizagem embasem as práticas e as interações que apoiam uma relacionalidade rumo ao 
Aliança de Ecoversidades

tornar-se amigos, compas $^{2}$, próximos entre si. Esta forma de relacionalidade parece muito diferentes do típico trabalho em rede orientado por objetivo que é encontrado em círculos acadêmicos ou de negócios.

O contexto do surgimento da Aliança de Ecoversidades é a trama de integrantes neste movimento de conhecimento. Esta trama começou em 2012, quando Kelly e Udi saíram dos cargos acadêmicos onde tinham lecionado sobre tais iniciativas e movimentos, para (re/des) aprender diretamente com esta paisagem diversificada de sistemas de conhecimento (lugares autônomos de ensino superior) que surgem dos movimentos sociais e ecológicos e das comunidades indígenas que florescem em todos os cantos do mundo. Em pouco mais de um ano, visitaram $^{3}$ e foram recebidos em mais de vinte lugares em treze países (Canadá, Estados Unidos, México, Peru, Argentina, Chile, Brasil, Nova Zelândia, Austrália, Tailândia, Índia, Portugal, Reino Unido). Reuniram-se com dezenas de inovadores criativos, corajosos, inspiradores e incrivelmente generosos em ensino superior e em outros espaços de aprendizagem (Teamey; Mandel, 2016). Durante esta jornada, um resultado inesperado foi a necessidade sentida de conectar diretamente estes lugares autônomos. Juntamente com Manish Jain, amigo e cofundador da Universidade Swaraj e Shikshantar Andolan, Kelly e Udi imaginaram reunir estas comunidades de aprendizagem em um encontro em que uma mutualidade de valores e práticas em solidariedade pudesse ser tecida.

A primeira parada da jornada de Kelly e de Udi foi o Red Crow Community College. Situado em um antigo internato missionário na Reserva Blackfoot no sul de Alberta, Canadá, a faculdade ensinava e intencionalmente reintegrava os saberes e as práticas tradicionais dos Blackfoot por meio de um paradigma cosmológico Blackfoot. Até a década de 1970, as crianças dos Povos originários eram retiradas de suas famílias para aprenderem a cultura dos colonizadores, os recém-chegados, por intermédio de uma política governamental de assimilação que tentava destruir a cultura indígena. No Red Crow College, Kelly e Udi aprenderam como o curso Kainai Studies ${ }^{4}$ estava ensinando a uma nova geração, tanto de Blackfoots como de não Blackfoots, ossaberes (e o idioma) que sustentaram as pessoas nesta região durante milhares dos anos ao reconectá-las à terra e a seus seres vivos.

Narcisse Blood, um idoso Blackfoot e cofundador do programa Kainai Studies relatou uma metáfora sucinta da universidade com as ecologias locais e outras formas de conhecimento:

\begin{abstract}
A base da nossa relação com os recém-chegados era o medo. O medo era na forma de fortes e aquelas muralhas altas que colocaram em torno de si mesmos para mantêlos em segurança contra os nativos e, assim, contra o meio ambiente. Para mim, aquela metáfora de um forte realmente se relacionava com as universidades. As universidades pensam que sabem tudo. Têm medo de sair de dentro daquelas paredes. Especialmente aqui na América do Norte. Olhe, tem conhecimento lá fora! (comunicação
\end{abstract}


pessoal e também dito no filme Re-learning the Land: $A$ Story of Red Crow College, 2015).

A imagem da universidade, como um forte, captura perfeitamente várias críticas da universidade modernista mencionadas acima. O fato de que o Red Crow College deveria reivindicar o espaço físico do internato, cuja finalidade explícita tinha sido destruir a cosmovisão e o modo de vida Blackfoot, é um lembrete poderoso daquilo que está em jogo para indivíduos, comunidades e suas ecologias quando falamos sobre guerras pedagógicas. Bruno Latour usa o termo guerras pedagógicas para descrever os últimos 500 anos de colonialismo e a imposição de cosmologias europeias sobre os colonizados (Latour, 2002). Grosfoguel (2013) descreve este processo como os quatro epistemicídios/genocídios no longo século XVI, processos de violência voltados para apagar os modos de saber e de ser das mulheres, dos muçulmanos e dos judeus, dos indígenas e das pessoas pretas. Foi a inauguração de um sistema político colonial, racializado, patriarcal e generificado ainda hegemônico no OWW buscando subjugar todas as possibilidades de mundificação.

Para o Blackfoot no Red Crow College, aprender e retomar o controle de sua educação foi uma forma de cura e de empoderamento (Chambers; Blood, 2010; Mandel, 2013). Embora enfrentando numerosos desafios (fundamentalmente neocoloniais), lugares como o Red Crow College e muitos outros espaços reinventando o ensino superior que se encontram dentro e fora da Aliança de Ecoversidades têm importantes insights, práticas e experiências a compartilhar que vão além de seu lugar de origem e seu contexto de luta. Como um experimento em aprendizagem cosmopolítica, a Aliança de Ecoversidades tem tentado compreender, praticar e incorporar o que estas lições de, entre e além destes lugares poderiam ser.

Tudo começou com uma reunião em uma ecovila em Portugal no verão de 2015.

\section{Como o encontro se reúne? A Cosmopolítica da Facilitação}

À medida que os participantes do $1^{\circ}$ Encontro de Ecoversidades de Pessoas Afins Reinventando a Educação começaram a chegar à Ecovila Tamera no sul de Portugal, fui ficando cada vez mais nervoso. Tínhamos construído este momento ao longo de vários meses, planejando e convidando as pessoas, e antes disso, durante um ano de viagens para muitos lugares, reinventando a aprendizagem e o ensino superior ao redor do mundo. Estávamos comprometidos com a abertura, a horizontalidade, o surgimento e a aprendizagem cosmopolítica e esperávamos que o convite tivesse deixado estas intenções claras. Além de uma infraestrutura organizacional mínima (inclusive um cronograma leve de sessões plenárias e de espaços abertos), estávamos, como diz o ditado, fazendo o caminho ao andar. Estávamos agudamente cientes de que a experiência poderia dar terrivelmente errado.

O que eu não tinha previsto era como a política, em nossa cosmopolítica, também iria enfocar algo tão mundano quanto a facilitação. $\mathrm{Na}$ 
Aliança de Ecoversidades

medida em que os dias se passaram, ficou claro que entre as diversas tensões que emergiram no grupo relacionadas aos contextos sócio-culturaishistóricos dos participantes, várias delas se centravam em torno de como deveríamos nos organizar como uma comunidade de aprendizagem provisória. Como profissionais de aprendizagem, todos éramos adeptos da facilitação; afinal, esta capacidade - "facilitar" (na etimologia da palavra) - é, uma característica de nosso ofício como educadores. O que não tínhamos previsto eram as reações que as pessoas teriam quando as suas práticas fossem questionadas ou quando as práticas de outras cosmologias fossem oferecidas para como se reunir. Ficou aparente que muitos educadores presentes, que tinham aprendido e praticado seu ofício em ambientes educacionais modernistas, tinham pressupostos implícitos a respeito do que constitui 'uma maneira apropriada de se reunir'. Os contornos destas práticas mudam, mas entre suas principais características podemos identificar a efetividade, fazer as coisas e ser produtivos ao aderir a um cronograma definido e autoexpressão. Em comparação, outras maneiras de se reunir eram influenciadas por cosmologias diferentes, especialmente aquelas afiliadas a contextos indigenas, priorizavam a contação de histórias, a escuta e a elaboração de consenso e relacionalidade - o que inclui tanto humanos como além humanos.

Meu nervosismo e ansiedade experimentados em meu corpo durante os dias do encontro também vinham do meu senso de responsabilidade pelo bem-estar dos participantes como um dos anfitriões que os convidou para lá. Eu sentia que os conflitos que tinham se seguido eram incômodos para alguns participantes - mesmo que no todo provassem ser regenerativos então e continuem sendo para todos os envolvidos, mesmo muitos anos mais tarde.

Aquele 'como facilitar', facilitação, deveria comprovar qualquer coisa, exceto ter sido uma aprendizagem importante em um encontro cosmopolitico. Batalhas ontológicas e coloniais eram claramente travadas. Sem dúvida, um pouco disso também derivava do investimento de egos e do orgulho profissional e apego a práticas e ferramentas individuais, e, como tal, uma reação a ser desafiado e perder o controle. Ao mesmo tempo, isso também aponta para algo mais profundo que temos aprendido continuamente na Aliança de Ecoversidades: dado que o Encontro em qualquer reunião cosmopolítica lança o alicerce para a conversa e o encontro entre ontologias ou práticas de mundificação, o modo como o encontro se reúne é da máxima importância. Ser explícito e transparente a respeito deste como, e cocriá-lo para honrar as distintas práticas e valores de reunião prepara o solo fértil para a emergência e o intercâmbio autêntico.

\section{Organização descentrada, escuta e a Festa Cosmopolítica}

Uma aprendizagem importante para muitos de nós na Aliança de Ecoversidades, e especialmente para nós que aqui escrevemos, é que a aprendizagem cosmopolítica, e ser um anfitrião ou coanfitrião de um encontro de cosmovisões como esse, envolve o descentramento da própria cosmovisão e um reconhecimento da força de gravidade do OWW. 
Parte deste descentramento é se abrir para outras maneiras de aprender e de ser, saber, fazer, relacionar-se e habitar por meio de uma abertura para experimentar aquilo com o qual possa se parecer. Juntamente com isso, outra parte deste descentramento envolve explorar faculdades não familiares em nós mesmos e em nosso estar (ou melhor, devir) no mundo - não apenas com a razão e o intelecto, mas também com nossos corpos e sentidos, nossa imaginação e sonhos, nossas relações com a terra e seus muitos seres. Estas práticas de se abrir para outros mundos dentro e além de nós mesmos acarretam escuta, atenção receptiva e abertura emocional à criação, que ainda é desconhecida e disforme. Essa "educação da atenção" (Chambers, 2008; Ingold, 2000) tem a qualidade de inter-ser com a qual abrimos este artigo, e promulga o suor de fazer cosmopolítica.

Nestes encontros, nossa ênfase era não apenas começar a compreender o mundo uns dos outros, mas também permitir encontros descentrados, transicionais (Escobar, 2018) com o mundo uns dos outros, para, de certa maneira, permitir a possibilidade de mundificar, de desacelerar, escutar profundamente e fazer cosmopolítica junto com uma série de práticas e eventos de convívio cocriados por nós. Em nossa experiência, o fazer cosmopolítico aconteceu menos através daquilo que pode ser formulado como uma política do encontro, mas mais por meio de convívio, ou a convivência - viver, ou comemorar juntos. A festa, a raiz do convívio e a etimologia de convivium, em nossos encontros de Ecoversidades eram compostos por numerosos ingredientes colhidos nas práticas de mundificação dos participantes de muitas regiões do planeta que são ao mesmo tempo coanfitriões e coconvidados, mas mais importante ainda, coaprendizes.

Até agora a Aliança de Ecoversidades realizou cinco encontros planetários (Portugal em 2015, Costa Rica em 2017, Índia em 2018, México em 2019, e on line em 2020), e doze encontros regionais (quatro no Sul da Ásia; dois nas Ilhas do Pacífico; dois na América Latina - no México e no Equador; dois na África - em Uganda e outro on line; um na Europa Mediterrânea - Itália; um no mundo árabe - na Jordânia; e um na América do Norte - on line). Ao longo destes encontros, os organizadores, uma mescla de pessoas que participaram anteriormente e anfitriões locais, aprenderam e aprimoraram a arte de organizar uma estrutura leve para que a vivacidade do encontro e a criação entre cosmovisões e no local possam surgir. Esta estrutura leve sempre é cocriada e deixa amplo espaço para a criação e para que os participantes reconfigurem o processo do encontro na medida em que se desdobra. Podemos chamar isso de Festa de Encontros de Ecoversidades. Esta festa está sempre mudando, mas alguns sabores - ou aprendizados - podem ser identificados nela. Os sabores do diálogo (trans)cultural, da aprendizagem experienciais e colocadas, do questionamento em solidariedade e política do cuidado, da cultura da dádiva, decolonizadora, e de criação têm sido uma característica destes encontros ${ }^{5}$. A cada encontro aprendemos mais, de maneira reflexiva e iterativa, como segurar o utensílio para este cozinhar e comemorar juntos para aperfeiçoar nossas práticas. Enquanto 
Aliança de Ecoversidades

o primeiro encontro no sul de Portugal, descrito acima, foi o pontapé inicial deste processo de cozinhar e comemorar, além de ter criado muitas perguntas, ondas e faíscas - algumas desafiadoras e desconfortáveis - gradativamente fomos aprendendo a aprender - ou cozinhar juntos, no espírito do 'ocupar nossas cozinhas', no qual reivindicamos "a esfera doméstica e, com ela, nosso senso de comunidade e alegria que vem do servir aos outros do coração de nossos lares: a cozinha" (Rivage-Seul, 2016). Embora não desejemos ser de maneira alguma prescritivos aqui nem oferecer uma receita em carbono, observamos em nossas experiências em encontros cosmopolíticos que existem alguns ingredientes chave que ajudam os sabores acima a emergirem. Também gostaríamos de enfatizar esta lista como alguns aprendizados e práticas chave incorporadas (suadas) e iterativas, em vez de categorias ou princípios abstratos seguidos por nós:

- Cerimônias, práticas espirituais, visualização - maneiras ritualísticas de se conectar um com o outro, a Terra e todas as criaturas vivas e não vivas;

- Trabalho somático - baseado na sabedoria do corpo, movimento, diversão, cura, respiração e incorporação de nossa camaradagem;

- Momentos discursivos - conversas, apresentações de diferentes projetos via espaços abertos, atividades facilitadas para refletir sobre linguagem, ações, gestos, sonhos, lutas em nossos contextos e como uma maneira de refletir sobre as metas e os desfechos da Aliança;

- Protocolos indígenas e autônomos - rituais e ferramentas para autogovernamento coletivo (pedagogia de aloha, asambleas, cargas...);

- Trabalho reprodutivo - preparação de alimentos, limpeza, cuidado de crianças, atividades manuais como construção, agropecuária e estar em serviço para apoiar os anfitriões e as necessidades da comunidade;

- Convívio - conversas espontâneas, performatividade, celebrações, música, refeições com a comunidade local, visitas à vizinhança e encontros com lideranças e profissionais locais;

- Aprendizagem em/com a terra - aceitar a ecologia de onde nos reunimos e seus arredores.

- Aprendizagem de yatra (peregrinação) - visitar e aprender com/a partir de lugares de aprendizagem local de diferentes tipos.

Se precisássemos analisar o recipiente oferecido por universidades modernistas, teríamos uma lista de receitas muito diferentes. Claramente os momentos discursivos seriam prioritários, raras vezes aprendendo com o lugar ou o contexto, dependendo das disciplinas em questão, contudo estariam quase invariavelmente confinados a uma cosmovisão de OWW. A universidade modernista é, por definição, projetada como um motor pedagógico e epistemológico do OWW. Embora 
alguns dos outros recipientes oferecidos acima surjam ocasionalmente em alguns contextos modernistas da universidade, raramente fazem parte, se fizerem, de um projeto combinado do todo da universidade como um lugar de aprendizagem e criação de conhecimento.

Na Aliança de Ecoversidades, coprojetamos pré-figurativamente nossos encontros de encontro para permitir um compartilhamento de espaço de convivência e emergente, oferecendo práticas, histórias e habilidades na medida em que emergem, por meio de uma abordagem de não-conferência. Desaceleramos para permitir que nós mesmos estejamos mais plenamente presentes e abertos ao que pode ocorrer, espelhando mundos imaginados de como outra educação pode ser possível. Experimentamos diferentes pedagogias e práticas, reunidas de modos que aprofundam nossa lógica e possibilidades relacionais, ocorrendo como oferendas isoladas ou em sequência com outras oferendas para permitir que exploremos mais lentamente, intencionalmente, a aprendizagem, abrindo novos espaços e mundos.

\section{Mapear e Mundificar a Nós Mesmos}

Deito no piso duro de lajotas. É o $4^{\circ}$ dos 5 dias do nosso $1^{\circ}$ Encontro de Ecoversidades. A pergunta pontual 'por que estamos juntos aqui' ainda está ecoando em meus pensamentos. Recém tínhamos terminado uma atividade com 3 horas de duração de desaceleração para refletir e articular uma resposta a esta pergunta em três folhas de hexagrama pequenas diferentes usando algumas palavras. A seguir, fixamos estes hexagramas em um espaço vazio na parede, todos nós, mais de 50, e começamos a nos mapear qualitativamente para saber onde enxergávamos linhas em comum entre nós, nomear estas linhas e depois refletir juntos sobre o que isto poderia significar. Passando para algumas horas mais tarde, de novo recebemos esta pergunta, mas por um facilitador diferente entre nós que muitas vezes coordena sessões de visualização. Ficamos sabendo que iremos entrar em um lugar de visualização parecido com um sonho. Tento acalmar minha mente, fechando os olhos e relaxando o corpo quando a sessão começa e nos dizem que estamos aqui agora com a intenção de receber uma visão a respeito de por que todos fomos enviados para este lugar, por que recebemos o chamado para vir e por que respondemos a ele. Somos solicitados a sentir o cheiro do lugar mais perfumado que podemos recordar, ir para essa lembrança e permitir que o aroma tome conta do nosso corpo. Meu corpo dá uma guinada e, de repente, estou em junho entre sálvia e zimbro, procurando pelo lobo selvagem porque é a estação. O calor do sol brilhante é bem-vindo entre uma leve friagem que permeia o fino ar da montanha. Subitamente, todo meu ser sente uma pura luminosidade por estar aqui. Então nos pedem para irmos para um lugar onde nos sintamos em completo uníssono com tudo que nos circunda, como se o batimento do coração da Terra fosse o nosso. Somos instados a escutar quem está tentando falar a cada um de nós neste lugar por meio de nossos batimentos e frequência cardíaca compartilhados. Sinto meu corpo se aprofundar e espalhar na Terra entre a sálvia e o zimbro. Escuto 
Aliança de Ecoversidades

sussurros de palavras antigas que não consigo traduzir conscientemente e minha respiração desacelera e relaxa com insights sendo emitidos de tempos imemoriais, de ancestrais vivendo e amando este lugar, esta terra, seus seres. Somos solicitados a ir para um lugar onde ficamos maravilhados com a beleza e para nos conectarmos com quem está criando aquela beleza e sentido de paz. Meu corpo paira através do amplo céu azul sobre os íngremes penhascos secos que cercam o lago de cor azul royal e os altos picos brancos. Enxergo a imensidão de margens reunindo marrons arenosos, perenes, azuis radiantes, pretos-carvão e brancos faiscando de texturas agudas, onduladas, pontilhadas e rosqueadas. Paro na margem do penhasco do lago azul com 600 metros de profundidade que foi lugar de adoração sagrada e silenciosa por milhares de anos. Embora eu tenha visitado este lugar centenas de vezes, meu corpo se enrijece com a magnitude do incrivel maravilhamento que de novo sinto ondular através de mim. A seguir, somos convidados a andar em uma floresta até uma trilha que conduz à água, a entrar na água e deixar-nos fusionar com a água, sentir o sol em nossa pele, o calor, o presente da vida, da luz enquanto desaparecemos na água. Caminho pela trilha íngreme até a borda do lago, passando sob os abetos de Douglas e pinheiros, observando uma águia planando sobre a água ao longe. Meu corpo, aquecido pelo sol incandescente que dá vida, se funde com a claridade intensa da água. Nosso convite final é para nos metamorfosearmos da água para uma forma, seguir os sons, a música em busca de uma visão que possa se formar em uma imagem que será presenteada ao grupo. Somos lembrados de trazer um guia para nos acompanhar ao longo de nosso trajeto. A música começa e de repente estou balançando com o ar, a água. Eu me transformo em uma gigantesca boca preta pegajosa, um deus da floresta irritado, se espalhando, procurando, crescendo e se movimentando rumo a todos aqueles que lá estão para extrair, para destruir, para consumir. Fico rolando cada vez mais rapidamente com raiva e, no entanto, meu corpo ainda está deitado no chão. Sinto uma aguda necessidade de me movimentar, correr, engatinhar, rastejar. E então uma calma voz calma me apazigua. Uma voz feminina, gentil, irreconhecivel. Faço uma pausa em silêncio. Um vórtex rodopiante interrompe a tranquilidade. Sou o próprio vórtex ou estou sendo girado pelo vórtex? Não sei dizer. Rodopio e rodopio, estou sufocando, sem fôlego. De repente, caio no solo da floresta. Há flores por todos os lados, flores selvagens em todas as cores imagináveis, flores selvagens que reconheço da minha infância, correndo em campos abertos que agora estão recobertos com gramados aparados e casas pré-fabricadas rapidamente construídas. Na medida em que caminho desta floresta para outra, existem álamos, sequoias, samambaias gigantes. O mar se desdobra à minha vista e existem alces, leões marinhos, dunas cobertas com longas folhas de grama sedosas. Sinto linhas de interconectividade tecendo cada espaço no meu corpo com tudo aquilo que enxergo, escuto, cheiro, sinto, saboreio. De repente, a música para. Solicitam que peguemos um papel e que permitamos que nosso corpo desenhe sem intelectualizar o que vemos, qual imagem queremos compartilhar, sem preocupação com ou por qualquer outra coisa, deixar nosso corpo criar. Somos lembrados de que a resistência também 
é um processo. Uma forma em preto se desdobra em minha página com raízes, braços, linhas emanando em uma brilhante variedade de plantas, flores e árvores. Também existe água, nutrindo tudo que está crescendo e sendo semeado. Então nos pedem para compartilhar o que a imagem está nos dizendo acerca do motivo de estarmos aqui, não como uma interpretação, mas o que é necessário a partir desta imagem para estarmos aqui. Meus sentidos são elevados e sinto como se estivesse escutando cada pessoa através de meu corpo, não de meus ouvidos. E parece que muitos de nós estão em um estado semelhante, pois existe uma gratidão enunciada em cada declaração. De algum modo viajamos além do tempo e do espaço durante esta visualização, sozinhos apesar de juntos. Fragmentos de memórias e sonhos, de lugares no passado com o presente, de ancestrais lembrando, ressuscitando... há lágrimas, vozes trêmulas, rostos incandescendo, esperança recentemente descoberta entre vestígios de trauma. Eu me encontro entre imagens de árvores, raízes, sementes, partos, mães, bebês, nuvens, oceanos, luz do sol, abelhas, borboletas. Combinações surreais de constelações celestiais em ramos de árvores, o topo das árvores segurando cabeças humanas e cabeças vegetais iluminando reciprocidade em um ser em fotossíntese. Eatravés de tudo isso, sinto o impulso e a tração, o yin e o yang da beleza e da dor, do sofrimento e da esperança.

De alguma maneira, por meio de nossas próprias viagens subconscientes, compartilhamos linhas de ruptura do espaço aberto e no aproximamos de nós mesmos e uns dos outros para semear e cultivar aquilo que pode vir a ser. Apesar de sermos oriundos de tantas terras e lugares diferentes, nos aproximamos de casa,, nossos oikos, de nosso propósito mais profundo de nos tornarmos plenamente humanos, despertando com humildade para a parcialidade de nossas próprias vidas que são entrelaçadas e interconectadas, nos reunindo para aprendermos e tecermos juntos nossas esperanças e nossa dor.

O que esta sessão de visualização iluminou para nós como um coletivo sobre o motivo de termos sido chamados para nos reunir? Nos momentos seguintes à sessão, seguiu-se um animado debate, revelando novos espaços de honestidade e esforço, de humor e diversão. Refletimos sobre a violência e a dor compartilhadas que muitos de nós continuamos a encontrar em nossas vidas cotidianas, embora diferentes em cada contexto, especialmente em sua magnitude. Refletimos sobre as possibilidades recentemente descobertas de esperança, de construção de solidariedade entre nós com outros mundos que são possíveis. Embora explorássemos as diferentes imagens que todos nós colocamos no papel em corpo e espaçol tempo subconsciente (por várias horas), também comparamos e contrastamos o que surgiu através da sessão de hexagrama antes da visualização. Estas conversas continuaram na refeição que compartilhamos mais tarde naquele dia, no encontro noturno no bar não alcoólico ao ar livre - e ainda continuam até hoje, mais de cinco anos depois deste encontro, oferecendo novos insights por meio de nossa inter-tecer relacional.

Não teria sido suficiente passar por este exercício de visualização em isolamento. O exercício de mapeamento racionalizado em hexagrama foi uma porta importante a atravessar antes da visualização. Em vez 
Aliança de Ecoversidades

de sermos atirados para dentro com pressa e de maneira inóspita, mergulhamos no nosso mundo próprio/uns dos outros mais lentamente, deliberadamente em nossa escuta profunda a nós mesmos e aos outros, encontrando/adentrando diferentes maneiras de saber, ser, relacionar-se e fazer, de abrir espaços em nossas mentes e então em nossos corações, nosso subconsciente - nossa consciência coletiva. A importância aqui era este fazer cosmopolítica. Ao invés de uma única parcialidade, um OWW, todos nós vivenciamos uma série de mundos, juntos e separadamente através do tempo e do espaço por meio de fragmentos de memória que se fundem com novos insights presentes, surreais e reais, revelando sobre nós e cada um.

Para muitos de nós, o exercício foi um retorno ao lar que desafiava qualquer conjectura racional. Em escritos posteriores a esta primeira reunião da Aliança de Ecoversidades, alguns participantes descreveram a multitude e a diversidade de aprendizados profundos que surgiram durante e após o primeiro encontro na Ecovila Tamera. Vários de nós refletiram que é precisamente a partir deste fazer cosmopolítica juntos, incluindo conflitos de cosmovisões (e egos), que qualquer descentramento significativo poderia ter surgido (Pomarico, 2018).

\section{Aprendendo em/com o Lugar e o mais que humano}

O primeiro Encontro Latino-Americano de Ecoversidades ocorreu entre 21 e 26 de agosto de 2018 no semideserto do Altiplano Potosino no México. Como uma maneira de descentramento, os integrantes da Aliança nesta região decidiram ser recebidos pela própria terra e não em uma instituição, como uma maneira de aprender com o lugar, com a complexidade da luta das pessoas para criar seus próprios espaços pedagógicos para revitalizar os saberes locais e para tecer uma tapeçaria de alternativas viáveis. A finalidade era habitar um contexto favorável à introspecção, com sobriedade e simplicidade na vastidão da sagrada terra de Wirikuta, uma matriz de vida. Eduardo Guzmán Chávez, participante no encontro e ativista de longo tempo na região, compartilha:

Wirikuta é um templo natural do mundo. É o Tibete espiritual onde a fertilidade é forjada e a saudável criatividade da humanidade é garantida. Seu subsolo está cheio de minerais. É uma caixinha de joias íntima onde a fecunda matriz de natureza pulsa (Guzmán Chávez, 2020).

Wirikuta é uma região com muitos projetos comunitários e com uma história que condensa experiências em comum da América Profunda, a presença de povos indígenas, colonização, assimilacionismo, mestiçagem, vida rural, projetos extrativistas, resistência, lutas e vida. Atualmente, existem ameaças adicionais de concessões de mineração (mais de 150.000 hectares para exploração mineradora nos próximos cem anos). O convite dos defensores de Wirikuta, nossos anfitriões e principais mestres durante o encontro, ressoaram em nós: “[...] parar o insaciável desenvolvimento de nosso delírio extrativista. É o coração. 
Vamos nos relacionar de maneira diferente com a natureza. Ela irá nos agradecer. Será a renovação do mundo. Um novo acordo. Cuidar da natureza irá nos alimentar" (Guzmán Chávez, 2020).

Interromper o delírio extrativista e aprender a se relacionar de maneira diferente com (nossa própria) natureza é uma tarefa cotidiana, sistêmica e não alcançada por decreto ou declarações comemorativas. É o convite de Wirikuta com seus universos simbólicos diferentes, as epistemologias e ontologias dos povos do deserto, indígenas e não indígenas, que exige a superação da colonialidade para conseguir florescer. Cocriamos no encontro um espaço onde este aprendizado e desaprendizado pode acontecer, relacionando-se conosco, com a terra, com os guardiões humanos e mais-que-humanos da terra, plantando a semente de um tempo diferente - não o tempo ocidental - por um acordo diferente de vida em Wirikuta, e no restante de nosso lar em comum. Escutamos as histórias da Frente de Defesa de Wirikuta para resistir à imposição do extrativismo e as relacionamos com o fogo que permanece aceso ao longo de todos os seis dias do encontro, dia e noite. Comungamos com os ancestrais e a sabedoria da terra em nossas oferendas no Bernalejo e escutamos as biografias que todos trazem de terras muito diferentes que também estão comungando e compartilhando temporariamente neste espaço de aprendizagem em que residimos por um curto piscar de tempo.

Durante a cerimônia de abertura, saudamos as direções, os elementais, os guardiões da terra, nos apresentamos uns aos outros para todos os seres atuais em nosso círculo originário, pedindo permissão para o trabalho que faremos. Recebemos o convite para a 'cerimônia de entrada', criar um espaço sagrado não apenas durante o tempo da 'cerimônia', mas para todo o encontro - oficinas, culinária, caminhadas, painéis e conversas se transformam em cerimônias. Com certeza, um compromisso desafiador, mas que esculpe a possibilidade para uma escuta profunda e de encontro entre os territórios que estão presentes e representados naquele momento, abertos ao que surgir.

Uma sugestão é que o encontro deveria ter uma fogueira acesa durante toda sua duração. É uma maneira de espelhar e oferecer nossa fogueira para plantar a semente desta nova tapeçaria de pessoas ligadas à defesa da vida e dos territórios com uma abordagem pedagógica. É uma maneira de cultivar nossa força coletiva e uma política do cuidado que inclui o encargo rotativo (um dever comunitário) de manter o fogo vivo, de dia e de noite. É a oportunidade de criar um espaço para se reunir, contar histórias, aquecer-se nas frias noites do deserto e compartilhar nossas intenções para a jornada que estamos a ponto de compartilhar. Também é uma maneira de honrar os guardióes daquela terra sagrada ao saudar e convidar esse espírito para nossas conversas.

A fogueira não tinha nenhum sentido do ponto de vista logístico. Era difícil mantê-la acesa mesmo que contássemos com o apoio de Ricardo, cuja tarefa principal durante o encontro era cuidar do fogo enquanto o restante do grupo fazia suas coisas. Porém, era um convite ao encontro, para manter aquela fogueira acesa coletivamente, para provar a nós mesmos que era possível, um ato de cuidado não-antropocêntrico. 
Aliança de Ecoversidades

Cuidar da fogueira provou ser mais complicado do que o previsto. Precisamos coordenar as atividades e o grupo está sempre se movimentando entre diferentes espaços da cidade. Ricardo deve ser alimentado e também precisa descansar. Há queixas de pessoas que não assumem a tarefa com seriedade ou de pessoas que não aparecem no seu turno. Alguns acham que é um espaço para ficar acordado a noite inteira e compartilhar música e histórias. Não existe nenhuma limitação ao consumo de álcool e algumas pessoas acham isso desrespeitoso naquele espaço sagrado, algumas pessoas são rudes, outras acham que é um espaço delicioso para ficar. Ao coordenar as diferentes atividades e a logística entre os espaços, sinto que não tenho tempo para responder às demandas e às vezes sinto que é uma desorganização total. Relembro a mim mesmo da ideia de ser um anfitrião descentrado, mas é difícil evitar responder às necessidades e às demandas das pessoas. Eu até mesmo penso qual é o sentido de fazer isto e me recrimino pelo dia em que tive uma ideia tão brilhante. Realmente não entendo o mundo dos espíritos, não sou indígena e não pertenço a nenhuma tradição específica. Estou sendo ingênuo demais? Estou sendo negligente?

Porém, o esforço coletivo sustenta a fogueira e sustenta o encontro. Muitas coisas dão errado. Precisamos sair do nosso hotel e encontrar outro lugar para nos abrigarmos, precisamos levar a fogueira para o novo local, os tijolos de adobe para os banheiros por compostagem que estamos construindo são entregues cinco horas depois do esperado, as pessoas têm queixas, preocupações, críticas.

Ao mesmo tempo, existe uma energia cálida, criativa, transformadora que também está alimentando nossas ações. Trabalhamos, aprendemos, desaprendemos, escutamos, brincamos, cozinhamos, comemos e sonhamos juntos. Estamos nas profundezas do deserto a céu aberto como sol ardente e todos estão concentrados em nossa cerimônia coletiva, conduzida por nossos amigos locais, na qual trazemos nossos pedidos e gratidão. Alguns reconhecem a presença de ancestrais e guardiões do território. Oferecemos nossas intenções para participar no cuidado e na regeneração de Wirikuta como uma matriz de vida. A maioria das pessoas entra no temascal (ou tenda de vapor) onde cantamos nossas esperanças e dores, apresentamos nossas orações e suamos juntos para morrer e renascer.

Nosso encontro termina e então encerramos com uma cerimônia. Nossa fogueira está apagada mas também viva nas experiências que tivemos naqueles cinco dias juntos, 40 pessoas de 24 organizações de 10 paises diferentes, plantando as sementes desta rede que estamos cocriando juntos, um espaço colorido (ch' ixi) para se relacionar de outra maneira, recordar, ser inspirado pela terra e seus guardiões, que nos lembram do profundo enraizamento do universo narrado pela história cósmica que coincide de algum modo nesta geografia e calendário, que nos une, 'fazendo afinidades' (Haraway 2016), profundamente, inevitavelmente relacionados em um compromisso com nossos parentes, "o fogo, o vento, a terra, o mar, a chuva, os cervos, as tartarugas, a rocha, as abelhas, o tlacuache e até mesmo os mestizos, porque somos ramos-frutos-flores desse milagre energético sem fim” (Guzmán Chávez, 2020). 


\section{CosmoConvívio e o desconfortável encontro de mundos coloridos}

Começamos este artigo com um convite para inter-ser. O espaço de encontro para esta possibilidade de inter-ser que temos vivenciado com e em é a Aliança de Ecoversidades, uma comunidade de prática de pessoas e lugares do mundo inteiro reinventando outros mundos de ensino superior. Dadas as múltiplas ontologias que os integrantes da Aliança trazem na medida em que fomos nos reunindo durante os últimos cinco anos, o conceito suado de cosmopolítica tem nos ajudado a compreender um pouco da dinâmica do que ocorre quando mundos tão diferentes se encontram e colidem. Compartilhamos algumas histórias que expressam a beleza e as tensões desta articulação de mundos que são encontros fugazes, mas possíveis entre os ancestrais, a terra, os movimentos sociais, o mais-do que-humano e o interontológico. Destacamos a importância de escutar, descentrar, cocriar e conviver como ingredientes chave da festa da aprendizagem cosmopolítica.

Dadas as múltiplas crises que vivemos e a cumplicidade do OneWorld World em reproduzir estas crises, precisamos de um novo acordo de vida. Temos a responsabilidade de cuidar da vida em si, o que envolve repensar a maneira como vivemos, a maneira como mundificamos o mundo, como indivíduos, como culturas e sociedades e como espécie. Como uma tarefa cosmopolítica, esta remundificação é urgentemente necessária e, por isso, é necessário gerar espaços de contato entre mundos onde a presença do outro seja respeitosamente reconhecida com consciência das múltiplas feridas, tensões e possibilidades que guardamos em nosso coração planetário compartilhado.

Silvia Rivera Cusicanqui compartilha o conceito Ayimara de $c h^{\prime}$ ixi como uma prática decolonizadora. Na cosmologia Aymara, $c h$ ' ixi se refere à cor cinza marmorizado formada a partir de uma infinidade dos pontos pretos e brancos que se unificam para a percepção, mas que permanecem puros e separados (Rivera Cusicanqui, 2018). O ch' ixi também está associado a determinados animais como a serpente ou o lagarto, que têm uma dualidade implícita em sua constituição. Para Rivera Cusicanqui, esta descrição multicolorida é útil para as realidades latino-americanas, pois revelam uma "[...] recombinação ativa de mundos opostos e os significantes contraditórios que tramam uma teia em cada margem daqueles polos antagonistas" (Rivera Cusicanqui, 2015, p. 226), de ancestralidade europeia e indígena. Estas tensões não são resolvidas pela mestizaje. Ao contrário, estas tensões estão apoiadas em permanente luta e contradição. O ch' ixi é uma prática decolonizadora porque não busca a fusão ou o hibridismo, mas aponta para a coexistência e o habitar estas contradições, sem negar suas partes ou procurar uma síntese.

Embora fundamentalmente aplicado à sociedade boliviana e, por extensão, latino-americana, o ch' ixi ressoa em todos nós porque somos histórias vivas com fortes contradições entre os múltiplos mundos que são articulados e incorporados em nós. O convite para todos nós é supe- 
Aliança de Ecoversidades

rar estas tensões em cada território, nos rebelarmos contra a identidade como uma camisa de força e, ao mesmo tempo, reconhecer a importância da identidade particularmente para aqueles grupos que foram historicamente visados por causa dela.

Assim, o espaço de inter-ser é colorido. Não apenas é apoiado por reciprocidade e harmonia, mas também se entrega a práticas de rompimento e movidas pelo poder. No reconhecimento destas tensões e das contradições que habitam cada um de nós, existe uma tentativa deliberada na Aliança de Ecoversidades de abrir espaços para aprendizagem que convide atos de rebeldia de um horizonte civilizatório diferente como uma possibilidade, tanto idiota por seu objetivo não ser induzir a ação, mas retardar o raciocínio e provocar o tipo de pensamento que nos permitiria desaprender a única ontologia da política (Stengers 2005; de la Cadena 2010) como utópica no sentido de um conceito e práticas incorporadas, suadas.

O fazer cosmopolítica, nesta articulação de mundos coloridos, exige o cultivo da arte do escutar, desacelerar o raciocínio para que o outro possa emergir em todo seu encanto, complexidade e contradições, sem ser outro nem ser igual, mas inter-ser. Sem a escuta, a cosmopolítica é vazia, pois é o ato de estar presente e ser aberta que permite o sentido de afinidade e o surgimento do convívio com o outro que também é nós. O nós da Ecoversidades não preexiste às relações que a constituem, o que é outra maneira de dizer que a Aliança, o sentido de comunidade, ou melhor, o sentido emergente de comunalidad ${ }^{6}$ colorida, não está garantido. Ao contrário, é ao escutar pacientemente, persistentemente e diligentemente que começa a aparecer um nós como uma possibilidade, um tipo de ser-mos dos mundos, um relance de um ecoverso.

Traduzido por Ananyr Porto Fajardo

Recebido em 16 de agosto de 2021 Aprovado em 19 de novembro de 2021

\section{Notas}

1 A comunidade indígena de Standing Rock, em North Dakota, Estados Unidos, protestou contra a construção de um gasoduto para envio de óleo em uma rota cruzando uma paisagem que é uma interface entre os níveis do cosmos. Mauna Kea se refere aos protestos de nativos havaianos contra a construção de um telescópio gigante no topo do Mauna Kea, um lugar sagrado considerado o zênite de seus laços ancestrais com a criação. Iremos descrever mais profundamente o caso de Wirikuta neste artigo.

2 Em espanhol, compa é um termo afetuoso (abreviação de compañero/a/e) para aqueles que compartilham de um sentimento mútuo de pertencimento a uma causa. A etimologia s refere àqueles que compartilham do mesmo pão.

3 Para um relato mais completo da visita como uma metodologia investigativa em solidariedade, ver Teamey, 2016. Aqui discutimos que apenas como parte deste movimento de conhecimento reinventando a universidade, também precisamos reinventar e desinstitucionalizar a pesquisa que abarca outras maneiras de saber, de se relacionar e de habitar. 
4 Os Kainai são um dos quatro grupos que fazem parte da Confederação Blackfoot em Alberta.

5 Para uma elaboração mais completa destes sabores, ver a lista de publicações e relatórios criados por integrantes da Aliança de Ecoversidades e disponível em https://ecoversities.org

6 Um conceito experiencial que permite a compreensão integral, total, natural e comum de "fazer a vida"' (Martínez Luna, 2015, p. 100) embasado nos quatro elementos de território, comunidade, trabalho e festa.

\section{Referências}

AHMED, Sara. Living a Feminist Life. Durham, NC: Duke University Press, 2016. ANDREOTTI, Vanessa et al. Mapping interpretations of decolonization in the context of higher education. Decolonization: Indigeneity, Education and Society, v. 4, n. 1, p. 21-40, 2015.

CASAS-CORTES, Maribel; COBARRUBIAS, Sebastian. Drifting through the Knowledge Machine. In: SHUKAITIS, Stevphen; GRAEBER, David. Constituent Imagination: Militant Investigations // Collective Theorization. Oakland: AK Press, 2007.

CHAMBERS, Cynthia M.; BLOOD, Narcisse J. Love thy neighbour: Repatriating precarious Blackfoot sites. International Journal of Canadian Studies/Revue internationale d'etudes canadiennes, p. 253-279, 2009.

CHAMBERS, Cynthia. Where are we? Finding common ground in a curriculum of place. Journal of the Canadian Association for Curriculum Studies, v. 6, n. $2,2008$.

DAY, Richard. From Hegemony to Affinity: The Political Logic of the Newest Social Movements. Cultural Studies, v. 18, n. 5, p. 716-748, 2004.

DAY, Richard. Gramsci is Dead: Anarchist Currents in the Newest Social Movements. London, England: Pluto Press, 2005.

DE LA CADENA, Marisol. Indigenous cosmopolitics in the Andes: Conceptual Reflections Beyond "Politics". Cultural Anthropology, v. 25, n. 2, p. 334-370, 2010.

DE LA CADENA, Marisol. Earth Beings: Ecologies of Practice across Andean Worlds. Durham, NC: Duke University Press, 2015.

DE LA CADENA, Marisol; BLASER, Mario (Ed.). A World of Many Worlds. Durham, NC: Duke University Press, 2018.

ESCOBAR, Arturo. Sentipensar con la tierra: las luchas territoriales y la dimensión ontológica de las epistemologías del sur. AIBR: Revista de Antropología Iberoamericana, v. 11, n. 1, p. 11-32, 2016.

ESCOBAR, Arturo. Designs for the Pluriverse: Radical Interdependence, Autonomy, and the Making of Worlds. Durham, NC: Duke University Press, 2018.

ESTEVA, Gustavo; PRAKASH, Suri. Escaping Education: Living as Learning in Grassroots Cultures. New York: Peter Lang Publishing, 2008.

FORD, Marcus. Beyond the Modern University: Toward a Constructive Postmodern University. Westport, CT: Praeger, 2002.

GROSFOGUEL, Ramón. The Structure of Knowledge in Westernized Universities: Epistemic Racism/Sexism and the Four Genocides/Epistemicides of the 
Long 16th Century. Human Architecture: Journal of the Sociology of Self-Knowledge, v. XI, n. 1, p. 73-90, 2013.

GUZMÁN CHÁVEZ, Eduardo. La espiritualidad wixárika en nuestros días. Ojarasca, n. 283, November 2020. Available at: https://ojarasca.jornada.com. $\mathrm{mx} / 2020 / 11 / 14 /$ la-espiritualidad-wixarika-en-nuestros-dias-8467.html. Acessed on: 02 Aug. 2021.

HARAWAY, Donna. Staying with the Trouble: Making Kin in the Chthulucene. Durham, NC: Duke University Press, 2016.

HARNEY, Stefano; MOTEN, Fred. The Undercommons: Fugitive Planning and Black Study. New York: Autonomedia, 2013.

INGOLD, Tim. The Perception of the Environment: Essays on Livelihood, Dwelling and Skill. London: Routledge, 2000.

INGOLD, Tim. Anthropology and/as Education. Routledge: London, 2017.

LATOUR, Bruno. War of Worlds: What About Peace? Chicago: Prickly Paradigm Press, 2002.

LAW, John. What's Wrong with a One-World World. Distinktion: Scandinavian Journal of Social Theory, v. 16, n. 1, p. 126-39, Jan. 2015.

MANDEL, Udi. Enlivened Learning at Red Crow Community College. Ecologist, Hartland, 2013.

MARCOS, Subcomandante. The Fourth World War has Begun. Le Monde Diplomatique, English Edition, Sept. 1997.

MARTINEZ LUNA, Jaime. Conocimiento y Comunalidad. Bajo el Volcán, Puebla, Benemérita Universidad Autónoma de Puebla, v. 15, n. 23, p. 99-112. Sept./ Feb. 2015.

NHAT HANH, Thich. Clouds in Each Paper. Mar 25, 2002. Available at: https:// www.awakin.org.

ORR, David W. Ecological Literacy: Education and the Transition to a Postmodern World. Albany, NY: SUNY Press, 1992.

ORR, David W. Earth in Mind: On Education, Environment, and the Human Prospect. Washington, DC: Island Press, 2004.

PELIAS, Ron J. A Methodology of the Heart: Evoking Academic and Daily Life. Walnut Creek, CA: Altamira Press, 2004.

POMARICO, Alessandra (Ed.). Pedagogy Otherwise: The Reader. Guelph: Ecoversities Alliance; Musagetes, 2018.

RE-LEARNING THE LAND: A Story of Red Crow College. Director: Udi Mandel. Costa Rica, 2015. 68 min.

RIVAGE-SEUL, Peggy. Occupy Our Kitchens: A New Feminism for Everyone. The International Journal of Illich Studies, v. 5, n. 1, p. 95-112, Nov. 2016.

RIVERA CUSICANQUI, Silvia. Sociología de la Imagen. Miradas ch'ixi desde la historia andina. Buenos Aires: Tinta Limón, 2015.

RIVERA CUSICANQUI, Silvia. Un Mundo Ch'ixi es Posible. Ensayos Desde un Presente en Crisis. Buenos Aires: Tinta Limón, 2018.

SANTOS, Boaventura de Sousa. Another Knowledge is Possible: Beyond Northern Epistemologies. London, England: Verso, 2007.

SANTOS, Boaventura de Sousa. The European University at Crossroads. Oficina do CES, Coimbra, n. 355, 2010. 
SANTOS, Boaventura de Sousa. The End of the Cognitive Empire: The Coming of Age of Epistemologies of the South. Durham, NC: Duke University Press, 2018. SHUKAITIS, Stevphen; GRAEBER, David. Introduction. In: SHUKAITIS, Stevphen; GRAEBER, David; BIDDLE, Erika. Constituent Imagination: Militant Investigations // Collective Theorization. Oakland: AK Press, 2007.

STENGERS, Isabelle. The Cosmopolitical Proposal. In: LATOUR, Bruno; WEIBEL, Peter (Ed.). Making Things Public: Atmospheres of Democracy. Cambridge: MIT Press, 2005. P. 994-1003.

TEAMEY, Kelly; MANDEL, Udi. A world where all Worlds Cohabit. The Journal of Environmental Education, v, 47, n. 2, p. 151-162, 2016.

TEAMEY, Kelly. Are Ecoversties the Future for Higher Education? Open Democracy, London, 2016.

TODO se Transforma. Composer: Jorge Drexler. Album: Eco. Montevideo: Sondor, 2004.

TORMEY, Simon. From Utopian Worlds to Utopian Spaces: Reflections on the Contemporary Radical Imaginary and the Social Forum Process. Ephemera: Theory, Politics and Organization, v. 5, n. 2, p. 394-408, 2005.

Udi Mandel concentra seu trabalho em práticas de aprendizagem animadas para regenerar ecologias e comunidades e para reinventar o ensino superior para que ofereça futuros esperançosos. Isto incluiu uma colaboração com movimentos sociais e ecológicos e comunidades indígenas do planeta inteiro.

ORCID: https://orcid.org/0000-0002-5311-0014

E-mail: udi@enlivenedlearning.com

Gerardo Lopez-Amaro se interessa pelo cotrabalho, pela pesquisa-açãoparticipativa com pessoas que vivem em territórios onde estejam ocorrendo experiência coloridas e práticas em torno do Buen Vivir e justiça cognitiva, climática e relacional, participando de um ecossistema planetário, transgeracional de aprendizagem para fazer nascer mundos de dignidade. ORCID: https://orcid.org/0000-0001-7577-2185

E-mail: gtupac.amaro@gmail.com

Kelly Teamey tem sido ativa nos campos do desenvolvimento e educação internacional/sustentável nos últimos vinte anos. Seu trabalho tem se concentrado em abordagens críticas à política e práticas educacionais em contextos de desenvolvimento internacional, observando especificamente como a educação, a aprendizagem e as pedagogias podem se tornam transformadoras, holísticas e sustentavelmente conectadas com ecologias e comunidades locais.

ORCID: https://orcid.org/0000-0002-2982-3364

E-mail: kellyteamey@gmail.com

Editor-chefe: Luís Armando Gandin

Este é um artigo de acesso aberto distribuído sob os termos de uma Licença Creative Commons Atribuição 4.0 Internacional. Disponível em: <http:// creativecommons.org/licenses/by/4.0>. 